\title{
Exploration of Practical Teaching Reform on Signal Processing Curriculum Group
}

\author{
Yuan NING \\ College of Electrical Engineering \\ Guizhou University \\ Guiyang, Guizhou, China \\ ee.yning@gzu.edu.cn
}

\begin{abstract}
The practical teaching reform of Signal Processing Curriculum Group has been an important part of the curriculum reform we devote to which include experimental teaching contents reform, experimental teaching system reform. According to training requirements of engineering applied talents in electrical information specialties, we propose a practice teaching system that is organized gradationally as follows: curriculum experiments, comprehensive trainings of DSP (digital signal processing) technology and its applications.
\end{abstract}

Keywords-signal processing; curriculum group; practice teaching; DSP

\section{INTRODUCTION}

DSP (Digital signal processing ) curriculum group, including Signals and Systems, Digital Signal Processing, Speech signal processing, Digital Image Processing, DSP chip theory and Applications, Embedded systems and applications courses and so on, which is the core course of Electrical Information Engineering major at most engineering university , has close relationship with each other.

According to training requirement of engineering applied talents, the practical teaching goal is said as, through studying the basic knowledge of courses, broadening knowledge of DSP ,improving the ability of practical application and fostering students' multiple ability of research study and practice innovation . Based on it, a practice teaching system has been proposed that is organized gradationally as curriculum experiments and comprehensive trainings of DSP including basic curriculum experiment, advanced comprehensive trainings experiment and innovative experimental teaching. The innovative experimental teaching is driven by research projects.

In this paper, starting with pointing out the objectives and design contents of Practical teaching about Signal Processing Curriculum Group, then, puts forwards practical-teaching reform mode on Signal Processing Curriculum Group .Lastly in section 4, conclusions are given.

\section{REFORM OBJECTIVES AND DESIGN CONTENTS OF PRACTICAL TEACHING ABOUT SignAL PROCESSING CURRICULUM GROUP}

\section{A. Practical Curriculum Teaching Reform Objectives}

The practical teaching reform objectives are to enable students to understand and use the basic theory knowledge of digital signal processing[1]. Firstly, the practical teaching goal of Signal Processing Curriculum Group is to enable students to understand the basic knowledge, including in the basic theories and analysis techniques of continuous time and discrete-time signals and systems, to make students systematically grasp the key teaching objective of the DSP courses, including the basic theory analysis techniques of signals processing such as Fourier and Z transforms, filter design, DFT and its implementation using the Fast Fourier Transform. Secondly, the practical teaching objective of Signal Processing Curriculum Group is to make students grasp the DSP application in image processing and speech processing. Lastly, to cultivate students engage in a related application and development by using professional devices such as DSP chips. Practical teaching curriculum reform consists of both the basic experiment related to the theory teaching content and the integrated experiment came from different curriculum courses should be designed for students.

\section{B. Practice Teaching Contents Design and Reform}

The DSP curriculum group practical teaching can be divided into basic curriculum experiment, advanced comprehensive trainings experiment and the innovative experiment, Each part of the practical teaching is designed according to the ideas which is "urgent need theory knowledge first, practice guidance, case-driven and inductive learning", and always carries "improve the application ability of students "which is the guiding idea. The experimental design is from shallow to deep, from basic experiments to integrated innovation, then to practical application, achieve the change that from the "single strengthen the theory" to "multiple research study and practical innovative ability" teaching mode to reach the goal to raise the innovative talents .

1)Basic curriculum experiment 
Basic curriculum experiment consists of the experiments of basic signal processing knowledge especially prior knowledge of discrete system including in the courses "Signal and System" and "Digital Signal Processing”, which belongs to the digital signal processing basic discipline theory knowledge experimental platform. The contents of basic curriculum experiment include sampling, z-transform, and basic filter design, DFT and its implementation using the Fast Fourier based on MATLAB, etc.

\section{2)Advanced comprehensive trainings experiment}

Advanced comprehensive trainings experiment contents focus on the two facets of applied DSP. The first aspect is applied experiment training through the course contents in "image processing" and "digital speech processing" that addresses the application in signal processing. The proposed experiments about first one are as follows:

- $\quad$ Speech signal acquisition.

- $\quad$ Process speech signals in time domain by finding pitch, short time energy, zero crossings, autocorrelation, windowing etc.

- Voiced/unvoiced segments by using FFT to estimate frequencies formats.

- Linear prediction coding model for speech segments and re-synthesize these segments.

- $\quad$ Speech signals compressing and decompressing .

- $\quad$ Histogram modification techniques.

- $\quad$ Spatial filtering of images, masking, etc.

- $\quad$ Noise removal from images.

- Image enhancement.

- $\quad$ FFT application in image.

- Image edge detection.

- Image compression.

The second aspect is hardware implementation training course in DSP chips/Embedded systems which serve as a connecting link between the theory and the application. The experiments are proposed as follows:

- Familiar with CCS (short for “code composer stu dio").

- $\quad$ MATLAB generate DSP code

- Image processing based on DSP toolbox.

- $\quad$ Speech processing based on DSP toolbox

The experiments also can be adopted with undergraduate project that wish to exposure to two fundamental applications of DSP. For example, "car license plate recognition "and "image watermarking". The former project would be a recognition processing project and the last one focus on waveform hiding inside an image.

\section{PRACTICAL-TEACHING REFORM MODE ON SIGNAL PROCESSING CURRICULUM GROUP}

\section{A. Reform Experimental Teaching System}

The important task to build a scientific and rational training scheme is to realize the change from the scientific knowledge type to the scientific knowledge practical skill based. So it must design rational of practical ability system for students, and overall planning every aspect of the practice teaching to form from low to high, from basic to the comprehensive knowledge, from the access granted the ability to foster an integrated, multi -level improved new teaching practice system. For signal processing curriculum group, we firstly integrated knowledge points of the signal processing course group and depurated knowledge link in these courses, revised the experimental program and the experimental instruction. Then, we combined MATLAB simulation and hardware experiments. After that, we combined confirmatory experiments and comprehensive experiments. Lastly, we optimize course practical training program and establish a perfect signal processing courses teaching system. For example, “digital Signal Processing” serves as the connecting link course between preceding and following courses, we cannot ignore the fact that the "digital Signal Processing" is the preceding course of hardware implementation courses, besides to design simulation experiments based on MATLAB, we add "familiar with CCS (short for "code composer studio) " into digital signal processing experiment course.

The new practice education system is divided into three levels, namely the basis experimental layer, design ability improvement layer, integrated application and technology activities layer. The three levels should not only be executed through professional teaching activities, but parallel with the theoretical teaching and coordinate and complement with each other.

1)The basis experimental layer

In the relevant courses, experiments based on MATLAB which can make students master theoretical knowledge[2].

2) Design ability improved layer

Advanced comprehensive trainings experiments Using MATLAB as a platform to provide students with a strong comprehensive, design and creative practice environment can not only cultivate the basis skill and practical ability, but improve overall quality.

\section{3)Comprehensive application layer}

Integrated application development layer can be carried out using DSP toolbox on real-time implementation of the actual subject of research, and the teaching, learning, scientific research are all promoted.

\section{B. Experimental Teaching Model}

Experiments can be classified into three categories: basic demonstration type, synthetic design type and creative research type experiments, can be practiced by ways of software emulation and synthetic hardware design. Although Simulation results which were interesting can stimulate the students' thirst for knowledge, the design and comprehensive 
experiments were increased in the practice training system, which can motivate students' innovation application initiative.

A practice teaching system has been proposed is organized gradationally as basic experiment and advanced experiment. Basic experiment includes basic demonstration experiments and preliminary design experiments. Advanced experiment consists of design and comprehensive experiments. Basic demonstration type experiments such as "Speech signal acquisition", "Frequency domain analysis" mainly are practiced by ways of MATLAB software which can consolidate and improve students 'knowledge level. In image processing course, basic experiments including "image enhancement", "image segmentation" etc. also can be realize through MATLAB language programming. Using MATLAB can help students come to understand the design ideas and improve students 'ability of analyzing and solving practical problems. It is noted that it is better to do basic demonstration type experiments synchronized with theory teaching. For synthetic design type and creative research type experiments, we need to encourage students to put forward their own new ideas. After innovative experiment design is verified by simulation, student can do real object hardware experiment on table. It becomes independent courses with a comprehensive application of simulation, hardware experiments, design and innovation made, such as "speech processing based on DSP chip experiment”, In the experimental process, firstly students should do virtual simulation about the experiment content that they would do, design all kinds of algorithm to reduce noise signal, test system performance using MATLAB simulation technology. It is very effective method especially for complex or hard-to achieve experiments in laboratory because the simulation system based on MATLAB makes experiment more flexible and vivid. Then, they could do the hardware experiment. Lastly, the algorithm should be implemented in hardware system.

\section{Fuse Many Practical Teaching Methods}

The teaching methods of a comprehensive experiment include both the software emulation and synthetic hardware designs are engaged to promote students 'knowledge mastering and flexible application.

In order to improve ability of analysis problem and resolve problem, we guide students to carry out practice by integrating knowledge of multiple courses, adjust the proportion of basic or validated experiments to design-type or integrated experiments and increase integrated and creative experiment projects. Students are lead in the practice gradually by basic, validated, design-type and integrated experiments.

\section{Construct Innovation Practical Teaching Platform of Curriculum Group Based on Research}

The design of innovative experiment based on research project, which directly affects the teaching effect , should be meet the demands of easy to moderate in the experiment design, rather than only simply integration. The innovation of experiment covering the knowledge points of the courses should be combing research projects, integrating curriculum teaching content and the knowledge point of the course .It is a fusion of research projects related to the contents together. For example, course design such as "license plate number recognition",” license plate segmentation" etc., are combined with the teachers' own research project. Besides, participating in extracurricular scientific activities is encouraged. Academic competitions, with the content extension of the project formed self-contained, collaborative, research-based experimental teaching methods.

\section{CONCLUSION}

The construction of signal processing experiment course group is curriculum system reorganization. According to training requirement of applied talents of electrical information specialties, a practice teaching system has been proposed which is organized gradationally as basic curriculum experiment and advanced comprehensive trainings experiment then innovative experimental teaching, which aims to improve students' capability of solving practical engineering application problems. As a result, the experiment contents and methods have been improved.

\section{ACKNOWLEDGMENT}

This research was supported by the teaching contents and curriculum system reform from the Undergraduate quality engineering key project of Guizhou Provincial Education Department. We thank all the anonymous reviewers for their valuable comments and constructive advices.

\section{REFERENCES}

[1] Liu Yi-min,Xu wang-min,Chen jian-liang,Wu Jin,You Xiang-bai, "Exploration and research on the construction of course group of signal and information processing” ,2010 international conference on E-health Networking,Dignal Ecosystems and Technologies,pp.304-306

[2] PAN Feng. Lin MIingxiu, Xue Dingyu, Chen dali, Cuij iangjiang, "Application of MATLAB in teaching reform and cultivation of innovation talents in university”, 2010 second international workshop on education technology and computer science.pp.700-702 